This item was submitted to Loughborough's Research Repository by the author.

Items in Figshare are protected by copyright, with all rights reserved, unless otherwise indicated.

\title{
Effects of applying EGR with split injection strategy on combustion performance and knock resistance in a spark assisted compression ignition (SACI) engine
}

\section{PLEASE CITE THE PUBLISHED VERSION}

https://doi.org/10.1016/j.applthermaleng.2018.09.001

\section{PUBLISHER}

(C) Elsevier

\section{VERSION}

AM (Accepted Manuscript)

\section{PUBLISHER STATEMENT}

This paper was accepted for publication in the journal Applied Thermal Engineering and the definitive published version is available at https://doi.org/10.1016/j.applthermaleng.2018.09.001.

\section{LICENCE}

CC BY-NC-ND 4.0

\section{REPOSITORY RECORD}

Zhou, Lei, Kai Dong, Jianxiong Hua, Haiqiao Wei, Rui Chen, and Yiyong Han. 2018. "Effects of Applying EGR with Split Injection Strategy on Combustion Performance and Knock Resistance in a Spark Assisted Compression Ignition (SACl) Engine". figshare. https://hdl.handle.net/2134/35202. 

performance and knock resistance in a spark assisted compression ignition

\section{(SACI) engine}

*Corresponding author: Haiqiao Wei

10 Address: 92 Weijin Road, Nankai District, Tianjin, P. R. China

11 Tel.: $+86-22-27402609$

$12{ }^{\#}$ These authors contributed equally to this work and should be considered co-first authors

13 Email: $\underline{\text { whq@tju.edu.cn }}$ 


\section{Abstract}

Spark assisted compression ignition (SACI) is a proven method for extending the load range and controlling the combustion phase of homogeneous charge compression ignition (HCCI) while maintaining high thermal efficiency. However, the occurrence of abnormal combustion, such as knock, limits the improvement of efficiency in SACI combustion. In this study, the effects of a coupling strategy, which combines internal/external exhaust gas recirculation (i \& e-EGR) and split injection, on knock suppression in SACI mode were investigated in a high-compression-ratio, single-cylinder gasoline engine with a fully variable valve system. During the experiment, the mass of intake air remained constant while e-EGR was added. The results show that the coupling strategy combines the advantages of e-EGR and split injection, providing an effective method for resisting knock and improving engine efficiency. The results also demonstrate that applying e-EGR to SACI combustion significantly decreases the knock intensity by effectively reducing the in-cylinder temperature. In addition, the effect of split injection on knock suppression is related to the initial in-cylinder temperature and fuel stratification. With high initial in-cylinder temperature, the relationship between

38 knock probability and split injection timing is non-monotonic. However, with low initial in-cylinder temperature, the capacity of resisting knock monotonically increases with the delay 40 of secondary injection timing.

41 Keywords: SACI, knock, internal EGR, external EGR, split injection

\section{Introduction}


improving the brake thermal efficiency $(\eta)$ and emission, and has attracted attentions of many researchers worldwide [1]. However, there are still challenges for HCCI, including the narrow load range and uncontrollable combustion phase. Intensive works have been carried out to extend the HCCI operating range, and strategies such as exhaust gas recirculation (EGR) [2, 3], split injection $[4,5]$ and intake boost strategies $[6,7]$ were proposed. In spite of all these efforts, the maximum indicated mean effective pressure (IMEP) of HCCI is still lower than $0.5 \mathrm{MPa}$ [8, 9]. Moreover, HCCI remains a challenge in combustion controlling due to lack of a direct ignition timing (IT) control mechanism [10]. Many researchers [11-15] have found that the spark assisted compression ignition (SACI) mode is a potential way to expand the HCCI load and control the combustion phase by adjusting IT.

With the aim of studying the mechanism of the SACI mode, different methods have been adopted in the last few years [16] to study the mechanism of the SACI mode. The SACI combustion process sequence was recorded by Wang $[8,17]$ and Benajes et al. $[18,19]$ with the use of the transparent engine. The conclusion can be summarized as follows: once the injection event finishes, the spark plug discharge will take place and consequently initiate the ignition and flame propagation process, in which the energy release causes an increase of pressure and temperature in the unburned gas zone, finally leading to a second phase of combustion governed by the auto-ignition of the rest of the mixture. In addition, Lavoie et al. [20] delineated the regimes to compare the different combustion modes in a multi-mode combustion diagram in terms of unburned and burned gas temperatures near top dead center. The analysis on experimental data suggests that SACI combustion mode is very suitable for the high and moderate loads to obtain the best performance, but the $\eta$ deteriorates as the load is reduced.

Additionally, in order to control the SACI combustion mode, different strategies have been proposed for adjusting the combustion phase and noise [9, 10, 21-24]. Many studies, 
including the experimental research of Olesky et al. [10] and numerical investigations by Robert. et al. [9], have also shown that the spark timing and in-cylinder temperature strongly affect SACI combustion phasing. The experimental results [10] show that the reduced peak of heat release rate (HRR) is achieved by controlling spark timing and unburned gas temperature with the fraction of flame heat release increased. The simulation results [9] show that the reduction in the peak HRR during the auto-ignition process is a function of both the end-gas mass and the end-gas reactivity. Another strategy deeply investigated by researchers is the split injection strategy [25]. Persson et al. [26] studied the SACI with ethanol as fuel in order to understand the effect of fuel stratification when using high speed fuel PLIF. The research result shows the occurrence of ignition in the mixing zone between the rich and the leaner regions. A parametric study was carried out by Benajes et al. [27], which was applied to the spark assisted partially premixed compression (PPC) ignition combustion mode under light load with the global lean equivalence ratio operating conditions. It was found that the split injection strategy can better realize the combustion phase control and improve combustion performance and emission performance compared with the single injection.

The above studies mainly emphasize on the mechanism of SACI combustion mode and the strategies of improving its performance. However, few researchers studied the knock phenomenon in SACI mode. The rapid auto-ignition of the end mixture can lead to the occurrence of knock phenomenon, thus limiting the increase of $\eta$ and producing combustion noise under SACI mode with high load [21]. The e-EGR and stratified mixture are the effective strategies for suppressing knocking in GDI engines [28-30]. However, there are few literatures reflecting the use of higher compression ratio (CR), e-EGR coupling with stratified charge to realize SACI.

91 Therefore, the present work experimentally and systematically investigated the effects of a strategy of internal/external EGR coupling with split injection on combustion characteristics 
as well as knock suppression in a higher CR-GDI engine with a fully variable valve train

94 (VVT). In particular, the impacts of the combined strategies on the pressure oscillation, knock measured by a wideband lambda sensor with a measurement accuracy and uncertainty of $\pm 0.1 \%$ intensity, HRR, in-cylinder temperature, $\eta$, etc. are systematically studied in this paper. The present work will give a valuable insight into the design of new engine.

The rest of this paper is organized as follows: section 2 describes the experimental facilities and operation conditions, as well as the evaluation methods for onset and intensity of SACI knock. Section 3 presents a detailed description of the effects on SACI combustion characteristic when e-EGR, split injection strategies, and e-EGR combined with split injection are adopted, respectively. Finally, the main conclusions of the study are presented in section 4 .

\section{Experiment study}

\subsection{Experimental setup}

The engine used for this experiment was a Ricardo E6 4-stroke SI engine. Details of the engine specifications are provided in Table 1. A schematic view of the engine and instrumentation setup is shown in Fig. 1. The cylinder bore, stroke, and compression ratio (CR) are $80 \mathrm{~mm}, 100 \mathrm{~mm}$, and 12:1, respectively. A double-spark ignition system was used in this study to guarantee stable combustion. The two spark plugs are symmetrically mounted on the cylinder head. The engine was equipped with a direct current dynamometer with a speed accuracy of $\pm 0.2 \%$. The in-cylinder pressure was measured by a pressure transducer (Kistler 6118B) mounted in the cylinder. The signal was then passed to a Kistler 5011 charge amplifier and finally to a National Instruments PC-612 data acquisition card. The equivalence ratio was and $\pm 0.8 \%$, respectively, and a response time within $0.15 \mathrm{~s}$. The SIEMENS Proportional 
115 Integral Differential (PID) controller measured the coolant and oil temperatures with an

116 uncertainty of $\pm 3^{\circ} \mathrm{C}$. All temperatures were measured with K-type thermocouples. The fuel

117 injection system is based on an electronic control unit (MOTEC M400). To achieve split

118 injection, a piezoelectric injector with a hollow-cone structure was used. Fuel mass was

119 measured by a fuel consumption meter with an accuracy of $\pm 0.5 \%$. Figure 1 shows the relative

120 position of the injector and the spark assembly in the cylinder head. This relative position

121 combined with the tumble flow was fixed to make the spray pass between the spark electrodes.

Table 1. Engine specifications

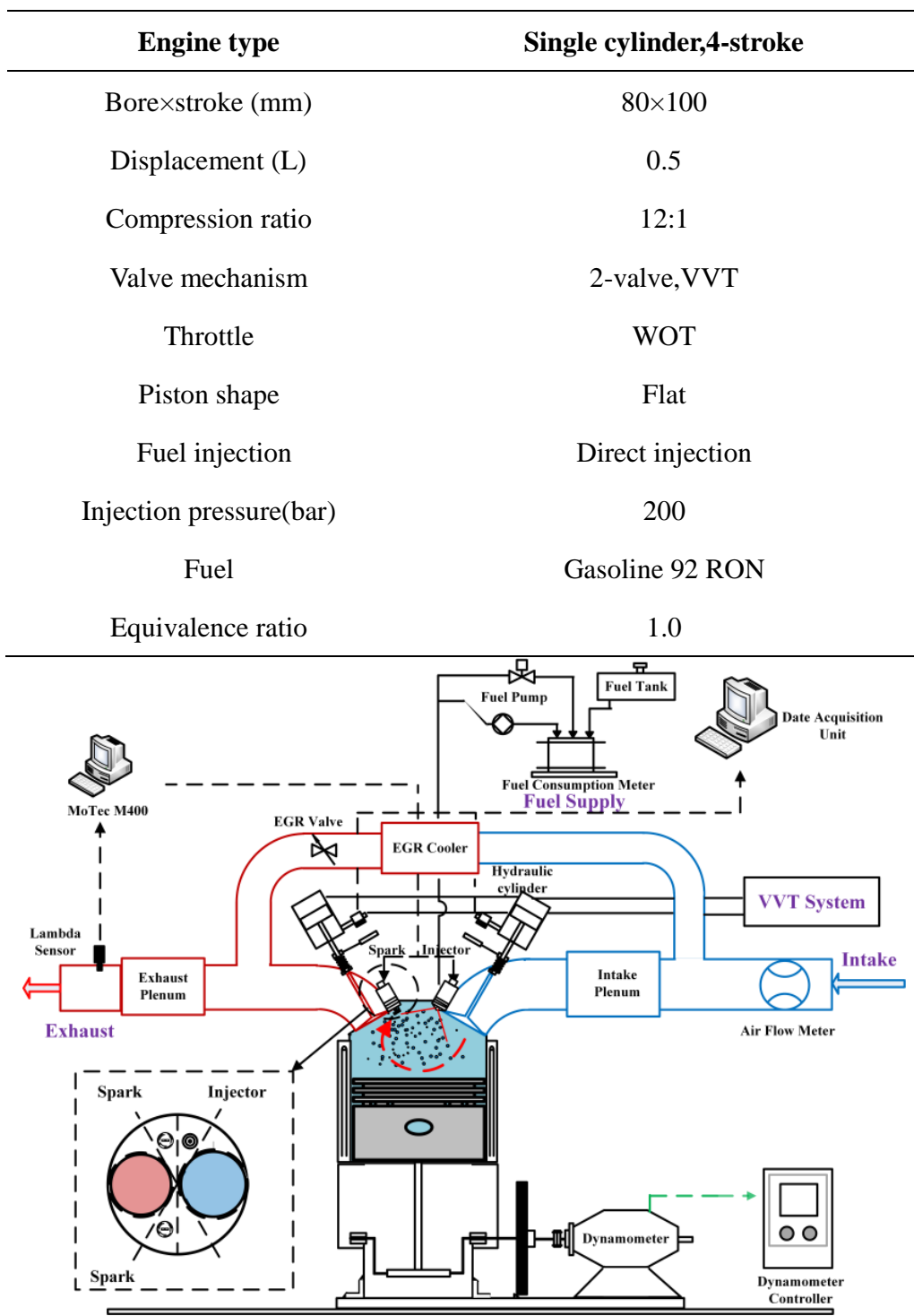

6 
electro-hydraulic valve train installed on both the intake and exhaust sides to achieve negative

valve overlap (NVO). The engine also has an e-EGR loop. The valve lift curves for the basic

NVO operation with fixed exhaust valve closing (EVC) and intake valve opening (IVO) timing calculated as follows in Eqs. (1), (2) and (3) [29, 31, 32].

$$
\left(m_{e-E G R}+m_{\text {air }}\right) * X O 2_{\text {man }}=m_{\text {air }} * X O 2_{\text {amb }}
$$
and $\mathrm{m}_{\mathrm{air}}$ are measurements of the injected fuel mass and intake air mass, respectively. $\mathrm{m}_{\mathrm{e}-\mathrm{EGR}}$ is the mass of e-EGR, which can be acquired from $\mathrm{CO}_{2}$ or $\mathrm{O}_{2}$ measurements in the intake and

140 exhaust pipes. $\mathrm{XO} 2_{\mathrm{amb}}$ represents the concentration of oxygen in the environment, and $\mathrm{XO} 2_{\operatorname{man}}$

141 represents the concentration of oxygen after the mixing of exhaust gas and intake fresh air

142 measurements in the intake pipe. $\mathrm{m}_{\mathrm{i} \text {-EGR }}$ is the internal residual mass and was estimated by

143 several different methods. The Mirsky Method, which is sufficiently accurate and requires 
144 simple calculations, was proposed by Yun and Mirsky and is chosen for calculating i-EGR ratio

145 [31]. $\gamma^{\gamma}$ represents the ratio of specific heats. The ratio of specific heats from EVO to EVC is

146 estimated by taking the average of the $\gamma$ values obtained using the temperatures at EVO and

147 EVC. When calculating $\mathrm{m}_{\mathrm{i}-\mathrm{EGR}}$, the value of 1.35 for $\gamma$ is utilised taking into consideration of

148 the existence of $\mathrm{CO}_{2}$ and $\mathrm{H}_{2} \mathrm{O}$, which are the primary substances in EGR gases. Additionally, it

149 was verified that the method of calculating $\mathrm{m}_{\text {i-EGR }}$ is not sensitive to the $\gamma$, suggesting that the

150 value selected in this paper is reasonable.

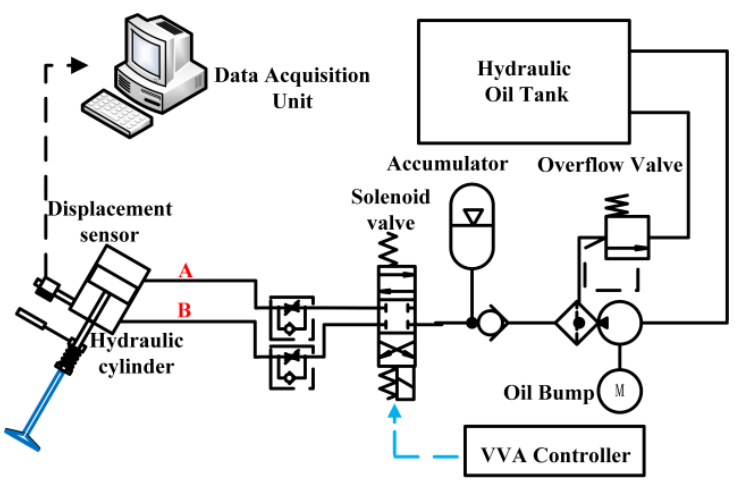

(a) Schematic of VVT System

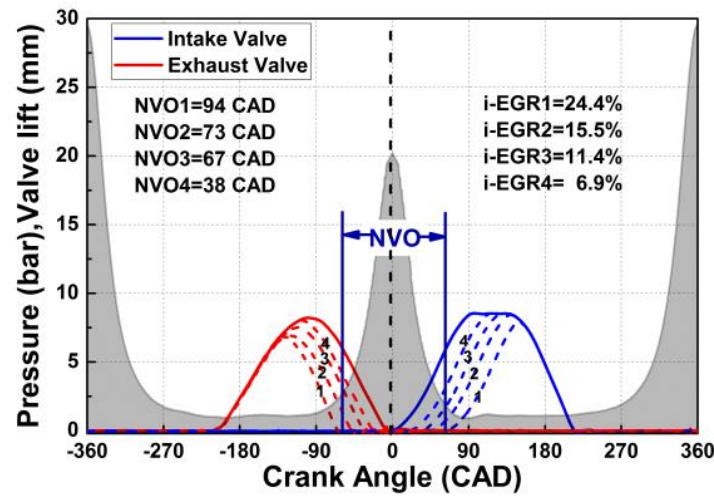

(b) Schematic of valve lift profiles

Fig. 2. Schematic views of the VVT system and the valve lift profiles for different SACI modes.

\subsection{Operation conditions}

152

After warming up the engine, it operates with wide open throttle (WOT). Measurements 
157 experiments was commercial petrol with research octane number of 92. Pressure signals were

158 obtained with crank angle intervals of 0.1 CAD for 200 consecutive cycles. The basic

159 measurements were as follows: a sweep of the symmetric NVOs, including $94 \mathrm{CAD}, 73 \mathrm{CAD}$,

$16067 \mathrm{CAD}$, and $38 \mathrm{CAD}$, was conducted, corresponding to i-EGR ratios of $24.4 \%, 15.5 \%, 11.4 \%$,

161 and $6.9 \%$, respectively. The injection control system makes it possible to modify any parameter

162 of the injection event, like injection timing, duration and rail pressure. In this paper, the start of

163 injection timing was set to be $300 \mathrm{CAD}$ BTDC in order to obtain a homogeneous charge. A

164 constant injection pressure of 200 bar was used for all measurements.

165 Table 2 shows the four groups of operating conditions studied in this paper. Group 1 aims

166 to study the effects of i-EGR ratios, which is realised by various NVOs with a single injection

167 and no e-EGR. Group 2 combines the i-EGR and e-EGR strategies, and intake mass flow rate

168 and fuel mass per cycle are held constant. This is achieved by simultaneously adjusting the

169 e-EGR valve and NVO. Group 3 is designed to study the effects of split injection strategies on

170 knock suppression and engine performance. Finally, the combination of internal/external EGR

171 strategies and split injection strategy are utilised to extract better engine performance and fuel

172 economy.

173

Table 2. Operating conditions for the different strategies.

\begin{tabular}{|c|c|c|c|c|c|c|c|}
\hline $\begin{array}{c}\text { Inject } \\
\text { Strategy }\end{array}$ & $\begin{array}{c}\text { SOI }_{1} \\
\text { (CAD BTDC) }\end{array}$ & $\begin{array}{c}\text { SOI }_{2} \\
\text { (CAD BTDC) }\end{array}$ & $\begin{array}{l}\text { ROI }_{1}: \\
\text { ROI }_{2}\end{array}$ & $\begin{array}{c}\text { Intake } \\
\text { XO2(\%) }\end{array}$ & $\begin{array}{c}\text { i-EGR } \\
(\%)\end{array}$ & $\begin{array}{c}\text { e-EGR } \\
(\%)\end{array}$ & $\begin{array}{c}\text { Fuel mass } \\
(\mathrm{mg})\end{array}$ \\
\hline \multirow{4}{*}{ Single } & \multirow{4}{*}{300} & \multirow{4}{*}{1} & \multirow{4}{*}{1} & \multirow{4}{*}{21} & 24.4 & \multirow{4}{*}{1} & 23.5 \\
\hline & & & & & 15.5 & & 28.7 \\
\hline & & & & & 11.4 & & 32.0 \\
\hline & & & & & 6.9 & & 36.1 \\
\hline Single & 300 & 1 & 1 & 20 & 13.9 & 3.9 & 28.7 \\
\hline
\end{tabular}




\begin{tabular}{|c|c|c|c|c|c|c|c|}
\hline & & & & 19 & 12.1 & 7.9 & \\
\hline & & & & 18 & 10.4 & 12.2 & \\
\hline & & & & 17 & 7.0 & 18.2 & \\
\hline \multirow{3}{*}{ Split } & \multirow{3}{*}{300} & \multirow{3}{*}{$180-60$} & \multirow{3}{*}{$4: 1$} & \multirow{3}{*}{21} & 24.4 & \multirow{3}{*}{1} & 23.5 \\
\hline & & & & & 15.5 & & 28.7 \\
\hline & & & & & 6.9 & & 36.1 \\
\hline Split & 300 & $180-60$ & $4: 1$ & 17 & 7.0 & 18.2 & 28.7 \\
\hline
\end{tabular}

174

175

176

177

178

179

180

181

\subsection{Evaluation methods for onset and intensity of SACI knock}

As reported in many previous studies, knocking combustion generates high frequency in-cylinder pressure oscillations ranging from $4 \mathrm{kHz}-20 \mathrm{kHz}[33,34]$. Therefore, a band-pass filter of $4 \mathrm{kHz}-20 \mathrm{kHz}$ is used to extract the pressure oscillations from the original in-cylinder pressure signal. According to Nyquist sampling theorem, the highest frequency component that can be analysed is one-half the sampling frequency. Under the conditions of the experiment, the sampling frequency is $90 \mathrm{kHz}$, which is sufficient to capture the knocking signal in the region of $4 \mathrm{kHz}-20 \mathrm{kHz}$. To quantify the intensity of engine knock, the maximum amplitude of filtered pressure oscillation (MAPO), which is calculated from filtered pressure, has been used as the knock indicator in this study. This indicator directly reflects the pressure fluctuation amplitude of knock combustion [35].

Statistical analysis is conducted to distinguish the conditions of normal combustion, critical knock and heavy knock under the SACI combustion mode, which is shown in fig. 3. In the experiment, no knocking sound was heard under the conditions of normal combustion. A slight knocking sound was heard under critical knocking conditions, and a sharp knocking sound was heard when heavy knocking occurred. In the fig. 4, with ITs during 4-10 CAD BTDC, no clear increases in the average MAPO can be observed. However, when the ITs 
191 change from 10 CAD BTDC to 14 CAD BTDC, the average MAPO clearly rises. Therefore, a

192 MAPO value of 0.2 MPa was selected as the knock threshold for the critical knock condition. If

193 the MAPO of an individual combustion cycle exceeds this threshold, it is regarded as a

194 knocking cycle. Furthermore, if the knocking cycle exceeds $10 \%$ for a given operating

195 condition, it is also considered a knocking condition [36]. Based on this methodology, the

196 conditions of normal combustion, critical knock and heavy knock can be well distinguished.

197

198

199

200

201

202

203

204

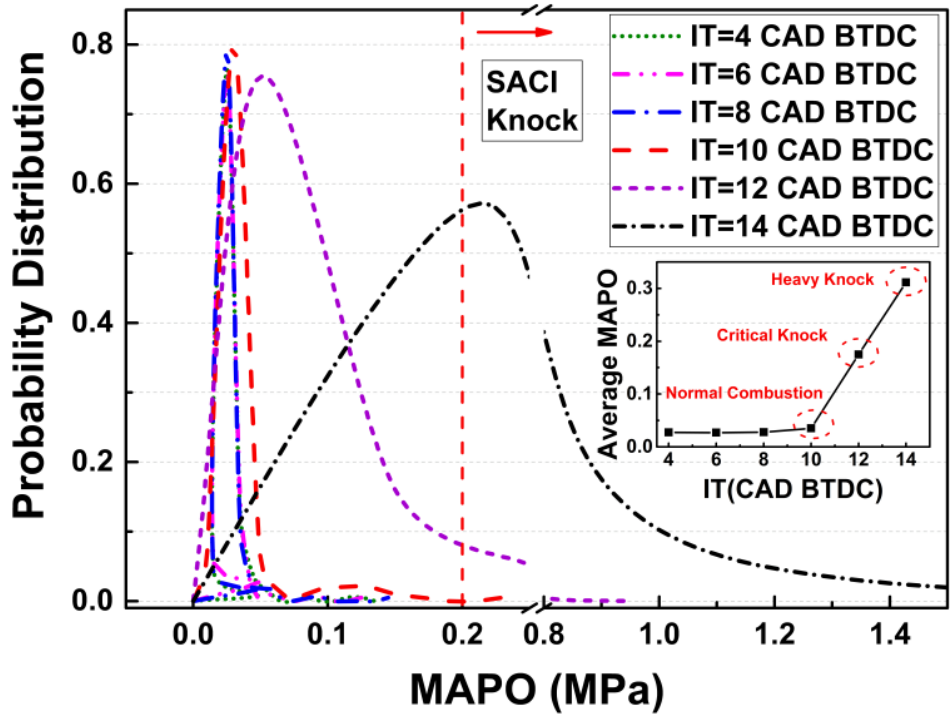

Fig. 3. Probability distribution of MAPO under SACI combustion mode.

Figure 4 compares the normal and knocking combustion process of the SI and SACI

modes. The pressures, pressure oscillations and HRRs are shown in Fig. 4. Note that the two combustion modes (SI and SACI) have the same control parameters (e.g., compression ratio, intake mass flow rate, fuel amount, equivalence ratio). When knock occurs, the knocking sound can be heard in both SI and SACI combustion. In the case of the SACI, the throttle was widely opened and the intake mass flow was adjusted by the NVO, while that of the SI conditions was controlled by the throttle open degree. Therefore, the in-cylinder pressure and 
207 higher initial temperature and pressure of the SACI, more fuel is involved in auto-ignition,

208 which leads to a faster burning rate and more intensive pressure oscillations than in SI

209 combustion. In other words, the knock intensity of the SACI is generally higher than that of the

210 SI. Additionally, the dashed lines show the normal conditions of combustion for the SACI and

211 the SI. The HRR of the SI is low and smooth, while the HRR of the SACI has an obvious

212 inflection point, which is the point at which auto-ignition occurs. Because of the effects of $\mathrm{CO}_{2}$

213 and $\mathrm{H}_{2} \mathrm{O}$ with regard to dilution and heat capacity, such auto-ignition is controllable and does

214 not result in an intensive combustion process. Consequently, this controllable auto-ignition

215 helps to improve engine performance.

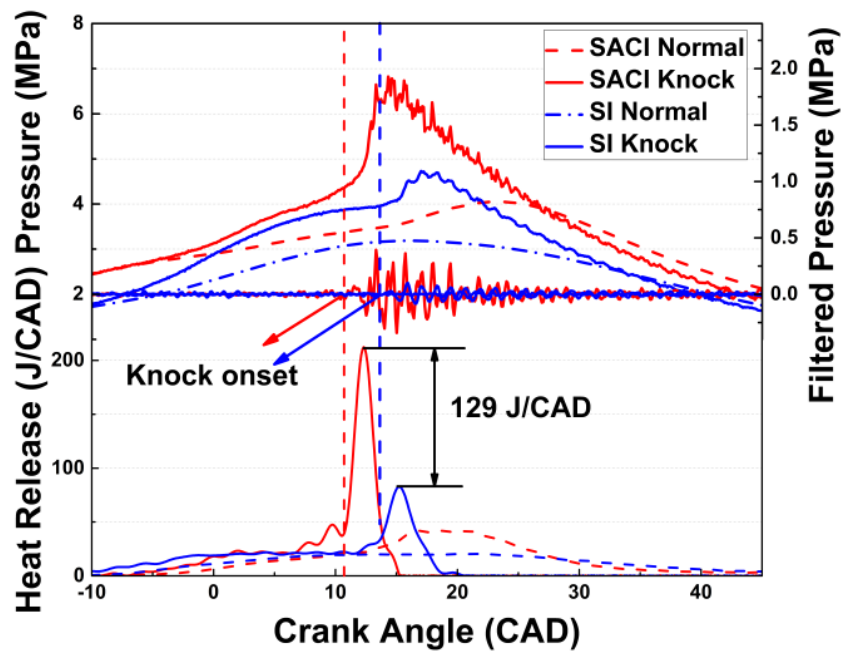

217 Fig. 4. Comparison of knock phenomena under SACI and SI combustion modes.

218 3. Results and discussion

219 3.1 Combustion characteristics with i-EGR (i-EGR strategy)

In this section to facilitate the analysis and comparison, preliminary results of tests using 
222 IT and i-EGR on SACI combustion mode, further research can be carried out on optimisation

223 by means of other strategies.

224 In this paper, the ratio of the amount of fuel consumed by flame propagation (SI

225 combustion) is defined as $\mathrm{R}_{\mathrm{si}}$. The auto-ignition timing of the unburned gas is defined as the

226 first maximum point of the second derivative of the $\operatorname{HRR}\left(\mathrm{d}^{2} \mathrm{HRR} / \mathrm{d}^{2} \varphi\right)[37,38]$. The value of

$227 \mathrm{R}_{\text {si }}$ is equal to the MFB value at the point of auto-ignition timing. The ratio of fuel consumed by

228 the CI process, $\mathrm{R}_{\mathrm{ci}}$, is equal to $1-\mathrm{R}_{\mathrm{si}}$.

229 Figure 5(a) illustrates the effects of different ITs on in-cylinder pressure, HRRs and mass

230 fraction burned (MFB) with an i-EGR ratio of $24.4 \%$ in the SACI combustion mode. It can be

231 observed that the peak pressure increases and advances while advancing the IT. Meanwhile, a

232 faster burning rate and shorter combustion duration can be obtained due to the earlier onset of

233 combustion. When advancing IT, $R_{c i}$ increases, exhibiting a higher HRR peak. This is because

234 advancing the IT can lead to higher in-cylinder combustion temperature and pressure, and the

235 ignition delay time of the unburned mixture decreases, thus leading to earlier auto-ignition

236 during the experiment, which prompts more fuel to participate in the second stage of the

237 compression ignition process. These effects lead to the CI process being overly violent and

238 generating strong pressure oscillations in the cylinder. Note that, as the IT is significantly

239 delayed, the heat release process gradually gets closer to that of the SI mode, and misfire cycles

240 occasionally appear during the experiments. This is because the combustion phase is delayed

241 when IT is delayed, and the combustion temperature and pressure in the cylinder are not

242 sufficiently large to cause auto-ignition of the unburned gas. In addition, the larger i-EGR rate 
243 reduces the stability of combustion. These results indicate that IT is a key parameter in

244 controlling the SACI combustion process. It can be found that, with appropriate i-EGR, the

245 combustion mode can be transitioned from SI to SACI by advancing the ITs [8]. It is important

246 to note that, when ignition is too early, it causes SACI knock.

247 Figure 5(b) illustrates the in-cylinder pressures, HRRs and MFBs of the minimum spark

248 advance for best torque (MBT) conditions at different i-EGR ratios. The MBT conditions are

249 determined by IT sweeps at each i-EGR ratio. As shown in Fig. 5(b), as the i-EGR ratio

250 decreases, the peak HRR increases gradually while the peak pressure drops slightly. Due to the

251 stoichiometric combustion in SACI, the decrease in i-EGR results in more fuel being injected

252 into combustion chamber, which increases engine load. To avoid knock when load rises, the IT

253 should be retarded, which slows the burn rate and lengthen the duration of combustion. Thus,

254 the decline in peak pressure can be observed as the i-EGR decreases. In addition, the decrease

255 in i-EGR results in an increase in $\mathrm{R}_{\mathrm{si}}$, which is due to the lower initial in-cylinder temperature

256 and longer ignition delay of the unburned gas caused by the retardation of the IT. Therefore, a

257 larger fraction of flame heat release is required to provide the additional compression heating

258 needed for auto-ignition. When the i-EGR is insufficient, the auto-ignition process in the SACI

259 mode diminishes due to the initial temperature being lower than the critical value. As a result,

260 the combustion transitions from the two-stage SACI combustion mode to a single-stage

261 traditional SI combustion mode. These indicate that i-EGR controls the combustion process of

262 the SACI mode mainly by controlling the initial in-cylinder temperature and ambient gas

263 components in the combustion chamber. 


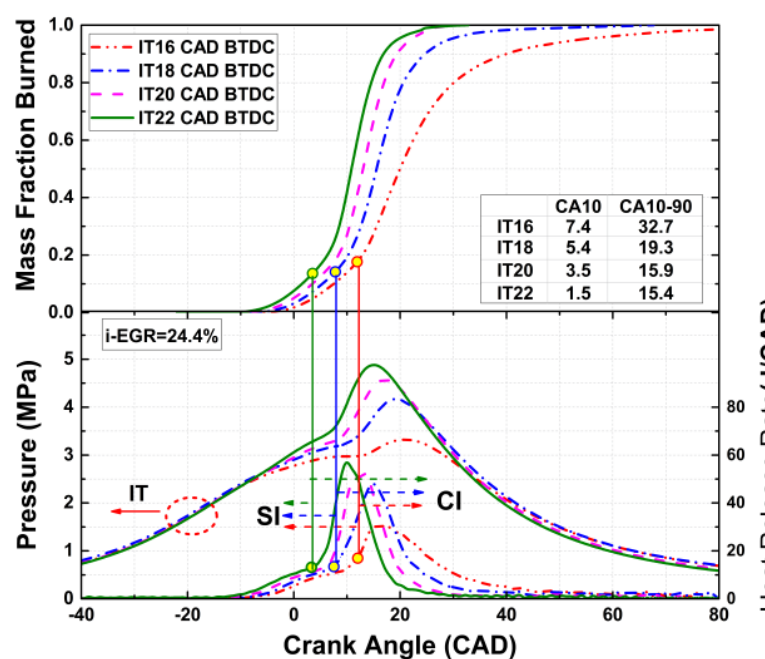

(a) Ignition timing variation

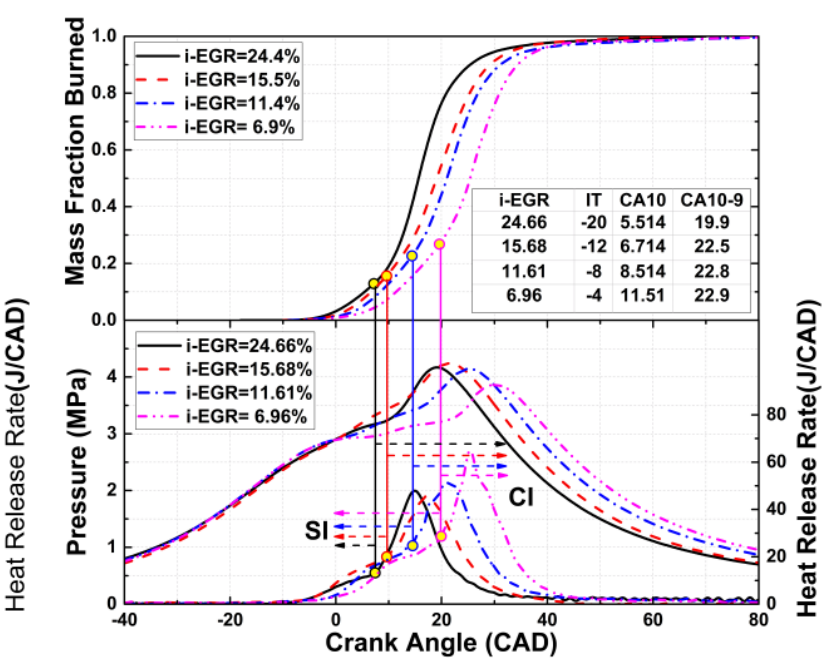

(b) i-EGR rates variation

Fig. 5. SACI pressure, heat release, mass fraction burned under different ignition timing

\section{and $\mathrm{i}-\mathrm{EGR}$ rates.}

Figure 6 shows the brake mean effective pressure (BMEP) and brake specific fuel

consumption (BSFC) achieved over the region of stable combustion of the SACI engine in this

experiment. As the i-EGR increases, the air/fuel mixture becomes more diluted, which requires

267 advanced IT to maintain combustion stability. It can be observed from Fig. 6(a) that the stable

268 combustion region of SACI can be made relatively wide by changing the i-EGR ratio and the

269 IT. The area beyond the stable region is the knocking region, in which the IT is relatively

270 advanced at a certain i-EGR ratio. Conversely, the area below the stable region is the instable

271 combustion region, in which the i-EGR ratio is relatively large and the IT is relatively retarded.

272 Meanwhile, the corresponding BSFC varies from $236 \mathrm{~g} / \mathrm{kW} \cdot \mathrm{h}$ to $242.8 \mathrm{~g} / \mathrm{kW} \cdot \mathrm{h}$ at the MBT

273 point, as shown in Fig. 6(b). At high load conditions, the operating range is relatively narrow

274 and the BSFC is slightly higher relative to those at the other conditions. 


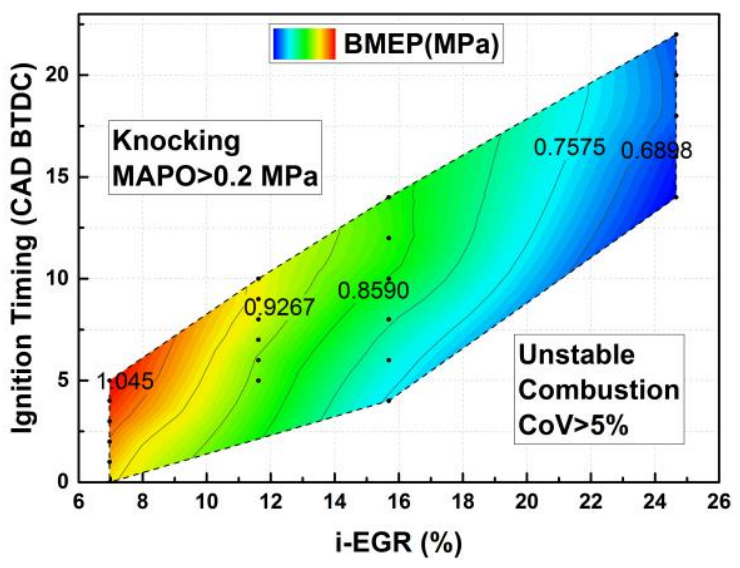

(a) BMEP of SACI

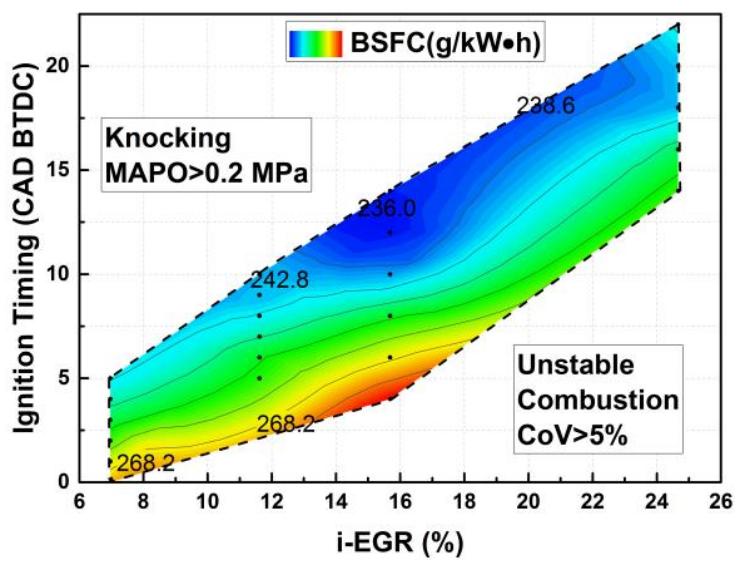

(b) BSFC of SACI

Fig. 6. BMEP and BFSC achieved over the region of stable SACI combustion at the stoichiometric condition. important issue that limits the $\eta$. This phenomenon warrants further investigation.

\subsection{Combination of internal and external EGR (i \& e-EGR strategy)}

In this section, the effects of a combined strategy utilising both internal and external EGR

282 (i \& e-EGR) on knock suppression and engine performance will be presented. The intake mass

283 flow rate and fuel injection mass are held constant at $17.8 \mathrm{~kg} / \mathrm{h}$ and $28.7 \mathrm{mg} / \mathrm{cycle}$, respectively.

284 When e-EGR is introduced into combustion chamber, the negative valve overlap (NVO) must

285 be adjusted to ensure constant intake mass flow rate. $\mathrm{O}_{2}$ concentrations (XO2) between

$28621 \%-17 \%$ are tested in this experiment, with the no e-EGR $(\mathrm{XO} 2=21 \%)$ condition designated

287 as the baseline case. 

combustion chamber, which is shown in Fig. 8.

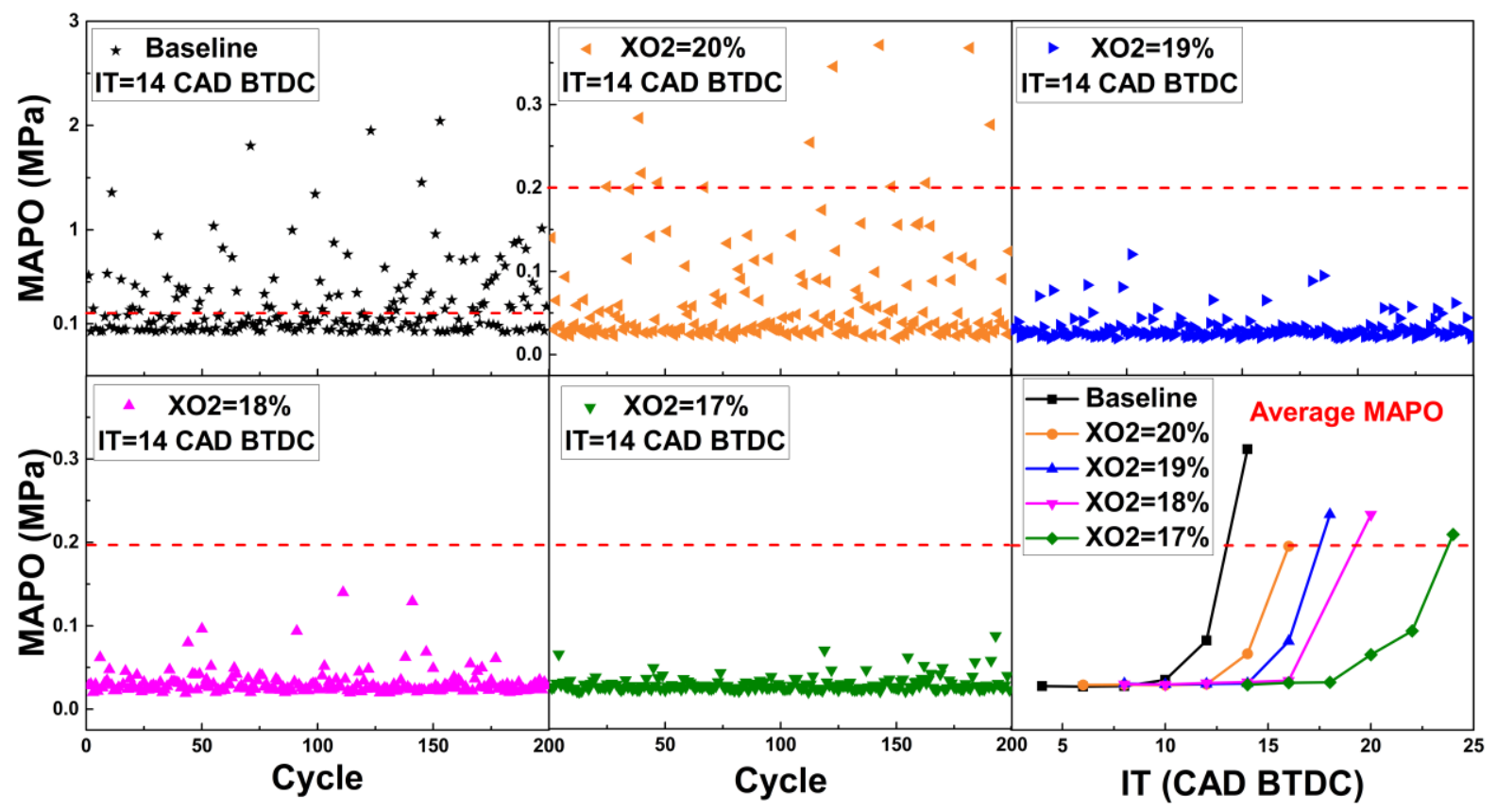


303 this study, the burned and unburned temperatures were calculated using a two-zone model [39,

304 40]. The calculation was performed using GT-Power software based on actual pressure data

305 collected from the experiments. As shown in Fig. 8(a), under the same operating conditions,

306 there is an obvious pressure oscillation in the baseline case. In the baseline case, the initial

307 in-cylinder temperature is relatively higher (Fig. 8(b)), leading to a decrease in the ignition

308 delay time of the unburned mixture. By introducing a large amount of e-EGR, the burning rate

309 reduces and the combustion duration is prolonged since both the SI and CI combustion stages

310 are suppressed [8]. These phenomena lead to a decrease in the $\mathrm{R}_{\mathrm{ci}}$ and the pressure oscillation,

311 thereby suppressing knock. This is because the initial in-cylinder temperature decreases with

312 the addition of external cooling EGR. At the same time, due to the gas expansion and

313 contraction characteristics, the total EGR in combustion chamber increases for further diluting

314 the fuel/air mixture. Consequently, more fuel participates in flame propagation and less fuel

315 participates in auto-ignition. . Therefore, the value of $\mathrm{R}_{\mathrm{ci}}$ in the baseline case is the largest and

316 the combustion duration is the shortest compared to the other cases. This indicates that the

317 effects of e-EGR on knock suppression are generally achieved by decreasing the initial

318 in-cylinder temperature and lengthening the ignition delay time of the unburned mixture, due

319 to the effects of dilution and heat capacity changing on the existence of $\mathrm{CO}_{2}$ and $\mathrm{H}_{2} \mathrm{O}$. 


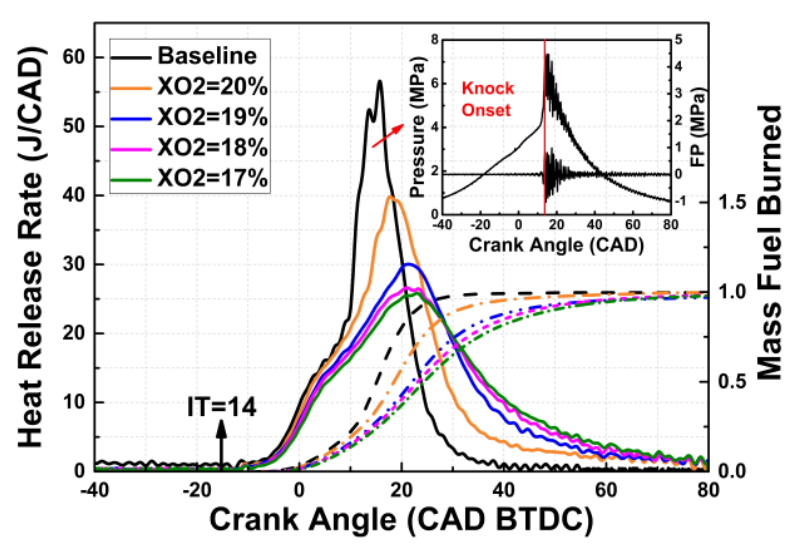

(a) Heat release rate and mass fraction burned

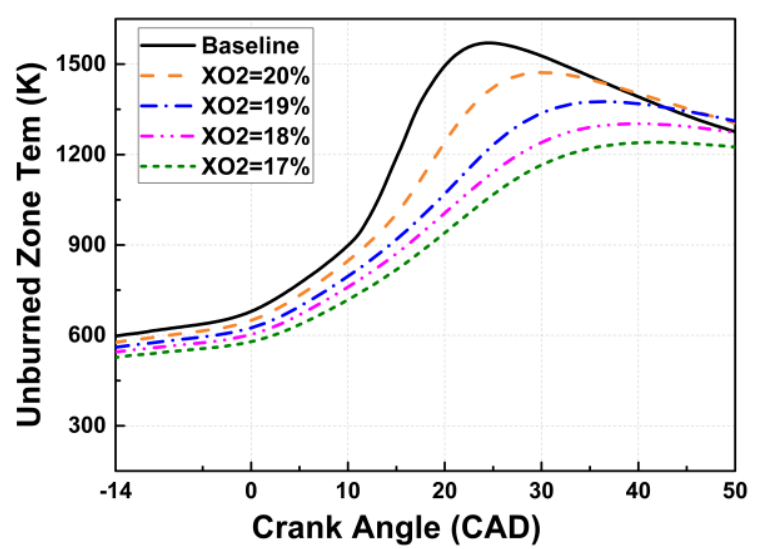

(b) Unburned zone temperature

Fig. 8. Comparison of combustion characteristics between the baseline and i \& e-EGR

\section{strategies.}

In addition to the knock-suppressing effect, the addition of e-EGR is effective in improving engine performance. Figure 9 shows the BMEP and BSFC at different ITs for the baseline case and the cases with varying i \& e-EGR strategies. As shown in Fig. 9, on the left of the red vertical dashed line (the MBT point of the baseline case), the BMEP declines and BSFC

324 increases with the addition of e-EGR at the same IT. After the baseline case reaches the MBT

325 point, further increase in IT leads to knock and a decrease in power output. As the e-EGR ratio

326 is gradually increased, the engine's capacity for knock resistance increases, allowing more

327 advanced ITs and higher BMEP to be achieved. The improvement in BMEP comes from two

328 factors - optimisation of the combustion process and lower compression work during the NVO.

329 As shown in the $\mathrm{P}-\mathrm{V}$ diagram, the maximum in-cylinder pressure of $\mathrm{XO} 2=17 \%$ with IT=22

330 CAD BTDC is significantly higher than that at the MBT point of the baseline case, which

331 results in higher output work (work ${ }^{+}, 20.9 \mathrm{~J}$ improvement). This is mainly because a faster

332 burning rate can be achieved by advancing IT. On the other hand, when a greater amount of 
333 e-EGR is introduced into combustion chamber, the NVO must be narrowed, which reduces

334 negative work and heat dissipation during re-compression of the residual gas. The negative

335 work (work) generated during the NVO reduces by $13.3 \mathrm{~J}$, as shown in the P-V diagram in Fig.

336 9. Essentially, more advanced IT and less negative work during the NVO period can be 337 achieved to optimise the combustion phase and engine performance, which leads to improved 338 fuel economy.

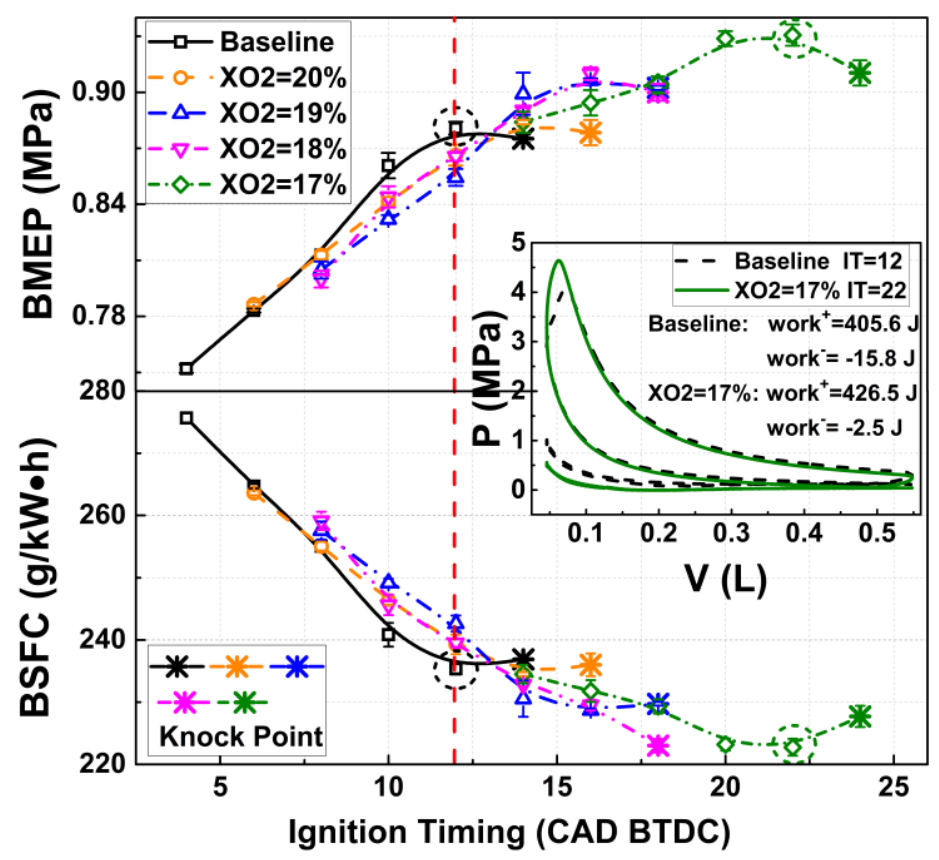

339

Fig. 9. BMEP and BSFC results for the baseline and i \& e-EGR strategies

341 ("work+" represent the positive work generated during compression stroke and power stroke).

\subsection{Combination of internal EGR and split injection (i-EGR \& Split strategy)}

In this section, the effects of a combined strategy utilising i-EGR and split injection 
347 of the first and second injection timings are denoted $\mathrm{SOI}_{1}$ and $\mathrm{SOI}_{2}$, respectively. $\mathrm{SOI}_{1}$ is set at

348300 CAD BTDC, similar to that of the i-EGR strategy, to ensure sufficient mixing time for fuel

349 injected by $\mathrm{SOI}_{1}$, which allows for the formation of a homogeneous charge. Setting $\mathrm{SOI}_{2}$ to

350 occur during the compression stroke can produce a weak stratified charge based on the first

351 injection [41]. The split ratios of $\mathrm{SOI}_{1}$ and $\mathrm{SOI}_{2}$ were set to be $4: 1$ in this section, which

352 corresponds the optimised split ratio determined by the experiment shown in Fig. 10. At the

353 MBT points of the different split ratios with an i-EGR ratio of $15.5 \%$, it is clear that the best

354 choice of split ratio is 4:1, which exhibits the highest BMEP. During the experiment, the cases

355 applying only i-EGR strategies with i-EGR rates of $6.9 \%, 15.5 \%$, and $24.4 \%$ are designated as

356 baseline cases. A sweep of the $\mathrm{SOI}_{2}$ from $180 \mathrm{CAD}$ BTDC to $60 \mathrm{CAD}$ BTDC in intervals of 40

357 CAD is utilised, with the $\mathrm{i}-\mathrm{EGR}=15.5 \%$ case being chosen as the example to analyse the effects

358 of $\mathrm{SOI}_{2}$ on knock suppression and engine performance.

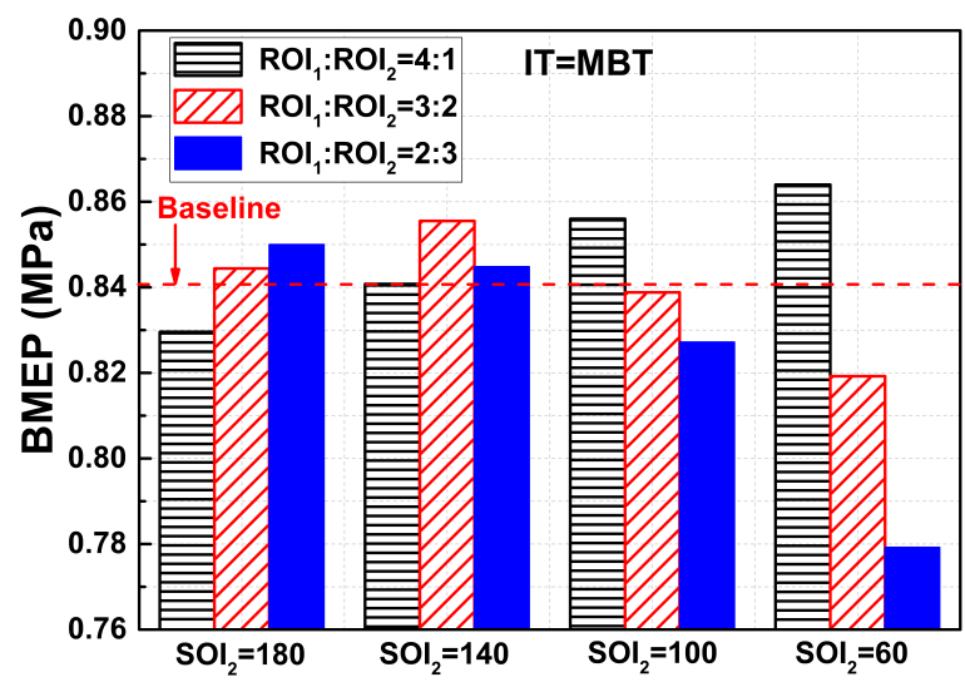

Fig. 10. BMEP with various split injection ratios of $\mathrm{SOI}_{1}$ and $\mathrm{SOI}_{2}$

Figure 11 illustrates the probability distribution of the MAPO with varying $\mathrm{SOI}_{2}$ and ITs.

362 It can be seen that, with a proper $\mathrm{SOI}_{2}$, the probability distribution of the MAPO is more 
364 advanced, the percentage of knock cycles gradually increased, and the MAPO distribution

365 became more dispersed. Few or no knock cycles occurred at values of IT corresponding to 8-10

366 CAD BTDC. When the IT was set to a value of 12-14 CAD BTDC, the MAPO probability

367 distribution gradually exceeded the knock critical value, and the percentages of knock cycles at

368 all operating conditions increased. However, except for the case with SOI2=60 CAD BTDC, in

369 which more knocking cycles occurred than that of baseline case at IT=14 CAD BTDC, the cases with $\mathrm{SOI}_{2}$ between $180 \mathrm{CAD}$ BTDC to $100 \mathrm{CAD}$ BTDC show a good potential for suppressing knock. These latter cases exhibit lower percentages of knocking cycles than the baseline conditions. This is due to different split injection strategies forming different types of fuel stratification in cylinder. The equivalence ratio being developed in different areas in

374 combustion chamber influences the flame propagation process and the later auto-ignition

375 process. Overall, the results indicate that knock can be effectively suppressed by split injection

376 with appropriate second-injection timings.

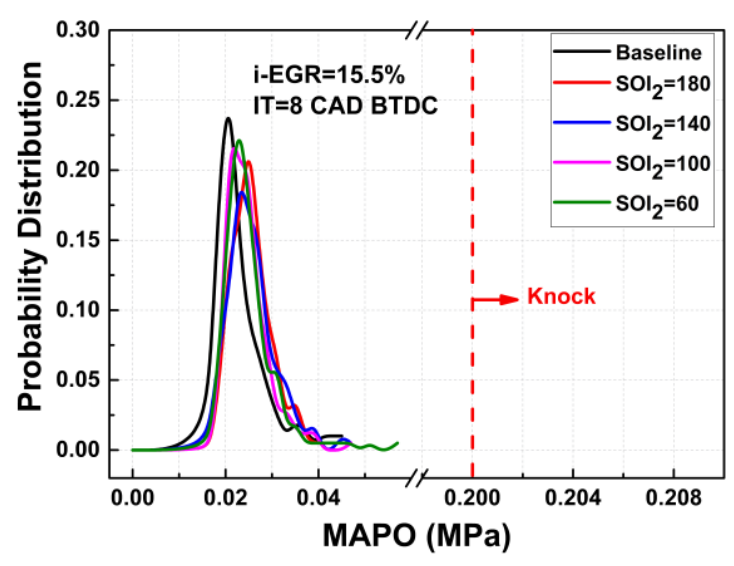

(a) IT at 8 CAD BTDC

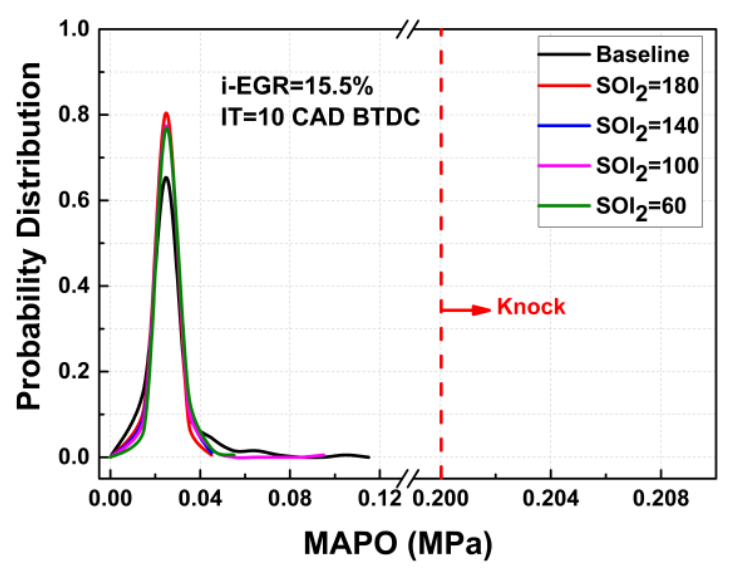

(b) IT at $10 \mathrm{CAD}$ BTDC 


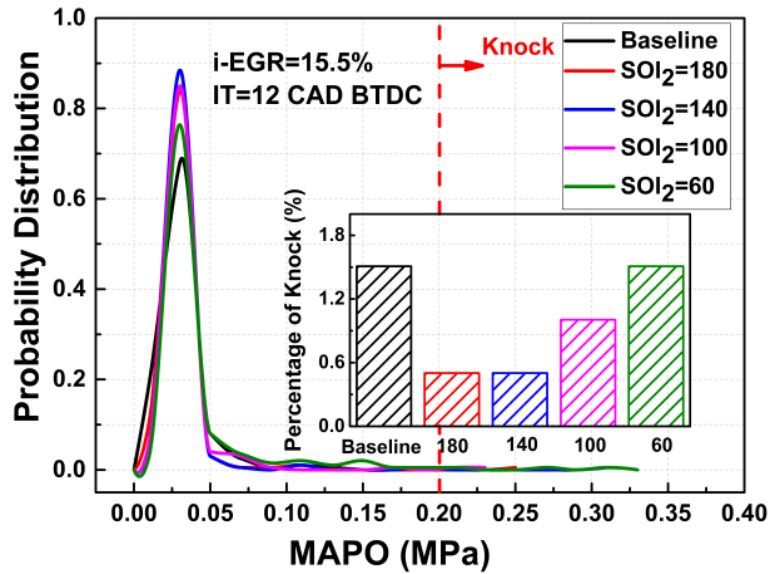

(c) IT at 12 CAD BTDC

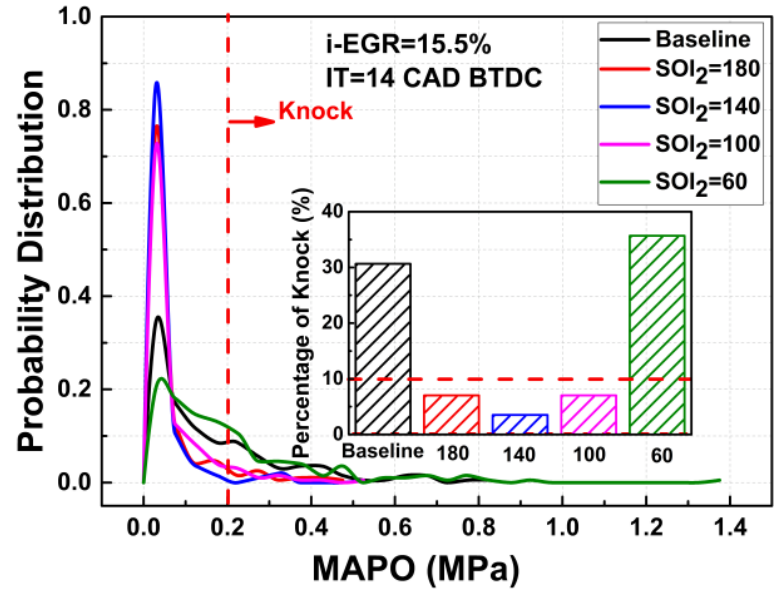

(d) IT at 14 CAD BTDC

Fig. 11. Knock probability distribution of baseline and i-EGR \& Split strategy at different $\mathrm{SOI}_{2}$.

CAD BTDC in the baseline case. Thus, the effects of split injection on knock resistance are

387 Consequently, the peak HRR gradually decreases and the combustion duration increases. 
rises substantially with a decrease in combustion duration. The level of stratification is

390 promoted by further retarding the secondary injection timing. At this point, the fuel/air mixture

391 in the region of near the cylinder wall becomes leaner, which leads to a higher temperature in

392 this region due to the attenuated cooling effect by fuel evaporation. The unburned zone

393 temperature in Fig. 12(b) demonstrates the weaker cooling effect of fuel evaporation at the case

394 of $\mathrm{SOI}_{2}=60 \mathrm{CAD}$ BTDC compared with cases of $\mathrm{SOI}_{2}=180 \mathrm{CAD} \mathrm{BTDC}-100 \mathrm{CAD} \mathrm{BTDC}$.

395 Under the effect of the heat produced by i-EGR and the compression of flame propagation, the

396 ignition delay time of the unburned mixture is shortened, which results in an earlier

397 auto-ignition and a larger percentage of knocking cycles. These results indicate that the ability

398 of the i-EGR \& Split strategy to suppress knock in the SACI mode is affected by the level of

399 fuel stratification. Moreover, the relationship between knock probability and $\mathrm{SOI}_{2}$ is

400 non-monotonic.

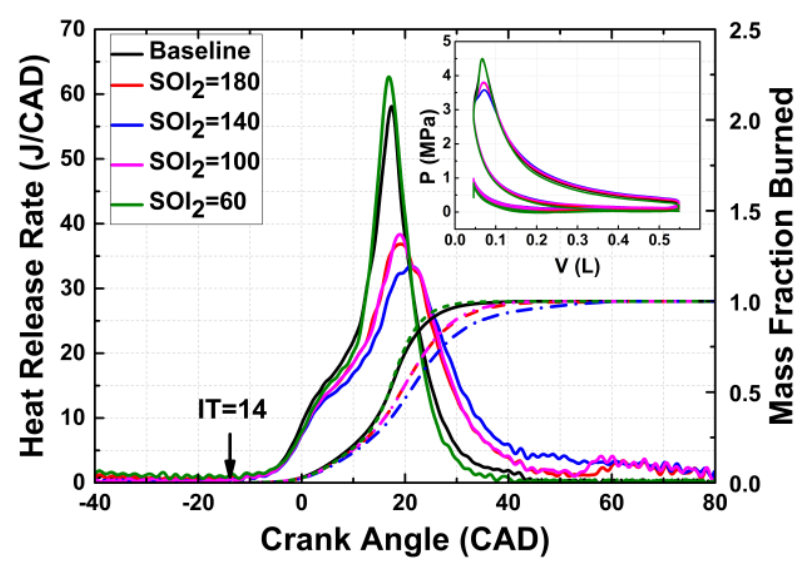

(a) Heat release rate and mass fraction burned

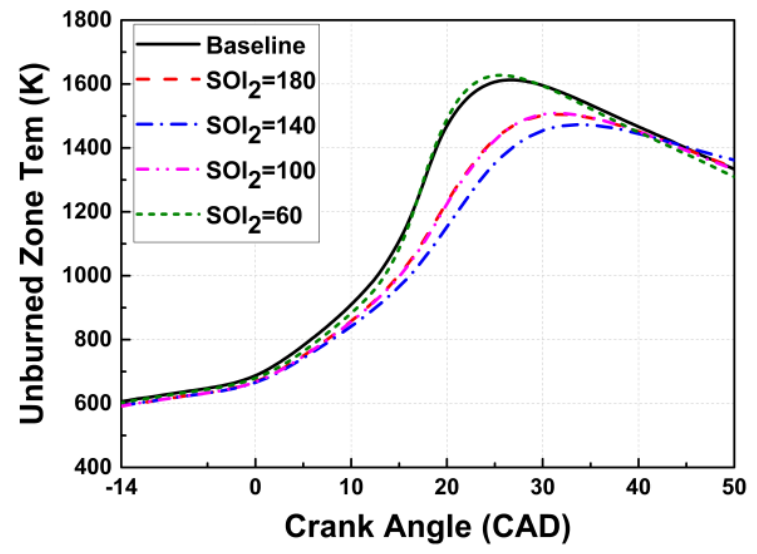

(b) Unburned zone temperature

Fig. 12. Comparison of combustion characteristics among the i-EGR strategy and i-EGR

\section{\& Split strategy at i-EGR=15.5\% .}


402 It can be seen from Fig. 13 that in the cases of i-EGR $=24.4 \%$ and i-EGR $=15.5 \%$, the ability of

403 the split injection strategy to suppress knock first increases and then attenuates with the delay

404 of $\mathrm{SOI}_{2}$. However, when the i-EGR ratio is $6.9 \%$, the knock suppression effect gradually

405 increases as the $\mathrm{SOI}_{2}$ is delayed. This is because the initial in-cylinder temperature is higher

406 when $\mathrm{i}-\mathrm{EGR}=24.4 \%$ and $\mathrm{i}-\mathrm{EGR}=\mathbf{1 5 . 5 \%}$, and the later auto-ignition stage is more sensitive to

407 the heat release of the early flame propagation stage. However, when i-EGR $=6.9 \%$, the later

408 auto-ignition stage is less sensitive to the heat release of the early flame propagation stage due

409 to a lower initial in-cylinder temperature. Overall, in SACI mode, the effect of knock

410 suppression by the split injection strategy is also influenced by the initial in-cylinder

411 temperature.

412

413

414

415

416

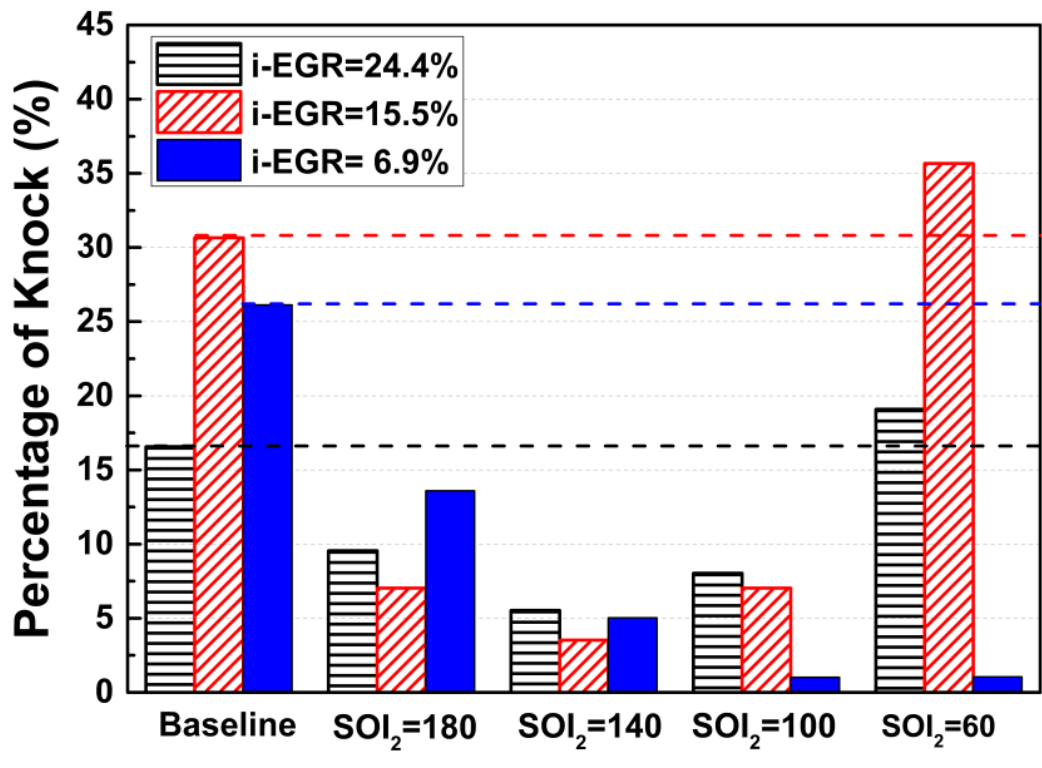

Fig. 13. Knock tendency of i-EGR \& Split strategy at different i-EGR rates.

Figure 14 illustrates the BMEP and BSFC of the single injection strategy and the split injection strategy at the MBT point at different i-EGR ratios. It can be observed, from Fig. 14(b), that the BMEP of the MBT point with split injection are greater than those of the 
417 baseline case. As noted in Fig. 13, when i-EGR $=24.4 \%$ and i-EGR $=15.5 \%$, a value of $418 \mathrm{SOI}_{2}=140 \mathrm{CAD}$ BTDC corresponds to the best split strategy with regard to knock resistance.

419 However, the best split injection strategy should produce the best BMEP while maintaining 420 acceptable knock intensity. With this in mind, the best split injection strategies occur when both 421 the knock resistance and power output are considered. As shown in Figs. 13 and 14(a), these optimal split injection strategies correspond to $\mathrm{SOI}_{2}=180 \mathrm{CAD} \mathrm{BTDC}, \mathrm{IT}=20 \mathrm{CAD} \mathrm{BTDC}$ with i-EGR=24.4\%, and $\mathrm{SOI}_{2}=60 \mathrm{CAD} \mathrm{BTDC}, \mathrm{IT}=12 \mathrm{CAD} \mathrm{BTDC}$ with i-EGR=15.5\%. It shows that the split injection strategy can directly influence the mixture formation process and, therefore, that it can produce changes in the combustion process. As a result, the secondary injection timing with the best knock suppression and that with the optimal power output are not necessarily in common. Figure 14(b) shows that BSFC of the i-EGR \& Split strategy decreases by approximately $4.06 \mathrm{~g} / \mathrm{kW} \cdot \mathrm{h}$ to $7.18 \mathrm{~g} / \mathrm{kW} \cdot \mathrm{h}$, which represents a significant improvement relative to the baseline.

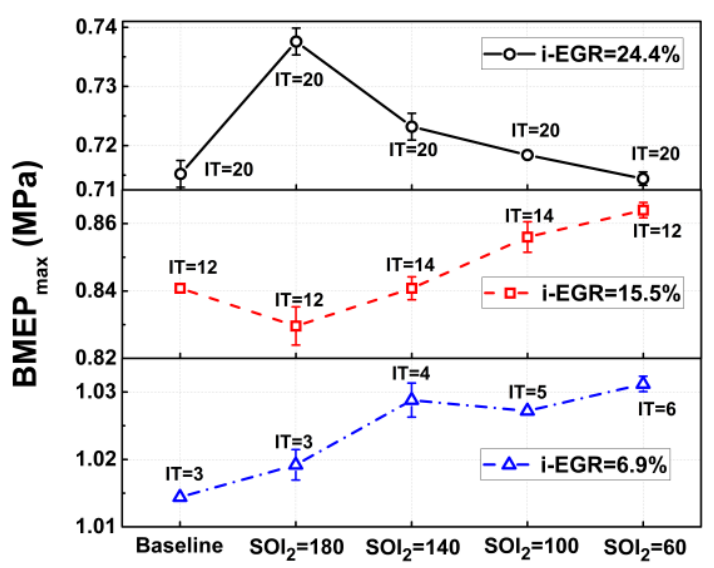

(a) BMEP

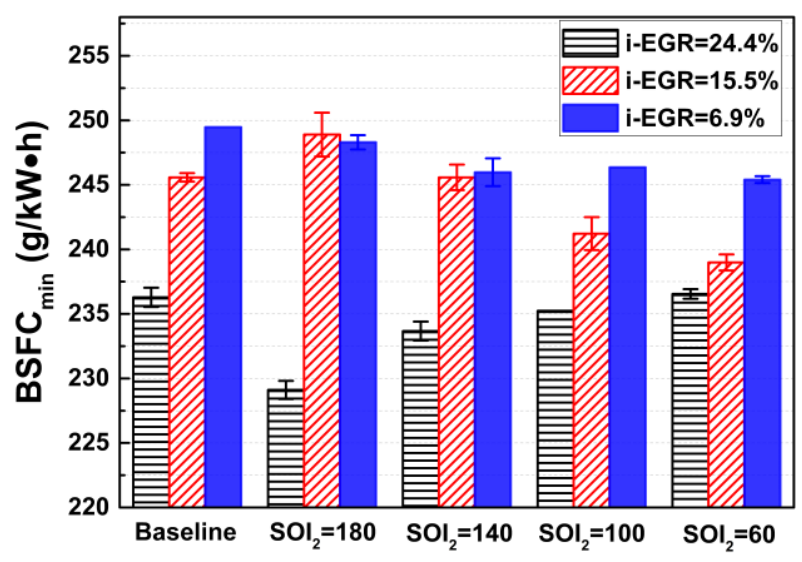

(b) BSFC

Fig. 14. BMEP and BSFC for the i-EGR strategy and i-EGR \& Split strategy at different

loads. 

strategy) This section presents an analysis of the effects of a coupling strategy, which couples internal/external EGR and split injection (EGR \& Split strategy), on knock suppression and performance optimisation in SACI mode. In this study, the fuel mass was maintained at 28.7 $\mathrm{mg} / \mathrm{cycle}$. At different operating conditions, the cases with the best anti-knock performance by adopting the optimal e-EGR ratio and $\mathrm{SOI}_{2}$ were selected to perform a comparison. Based on the results from the previous sections, the optimal secondary injection timing for the i-EGR \& Split strategy and the optimal e-EGR ratio for the i \& e-EGR strategy are 140 CAD BTDC and $\mathrm{XO} 2=17 \%$, respectively. The strategy with $\mathrm{XO} 2=17 \%$ and $\mathrm{SOI}_{2}=100 \mathrm{CAD} \mathrm{BTDC}$ is selected 440 for the study of the EGR \& Split strategy.

Figure 15 shows a comparison of the pressure and filtered pressure in the SACI mode for different strategies, including the i-EGR strategy, the i-EGR \& Split strategy, the i \& e-EGR strategy, and EGR \& Split strategy. Figure 16 illustrates the percentage of knocking cycles and the maximum pressure in SACI mode for different strategies. From Fig. 15 and Fig. 16, it can be seen that the knock tendency of the baseline case is higher than that of any other cases, with the MAPO reaching approximately $1 \mathrm{MPa}$ and the percentage of knock cycles reaching $30.7 \%$.

447 The MAPO and percentage of knocking cycles for the i-EGR \& Split strategy are 448 approximately $0.2 \mathrm{MPa}$ and $3.5 \%$, respectively. On the other hand, the MAPO is relatively low 449 and no knocking cycles occur with the i \& e-EGR strategy. These results imply that the e-EGR possesses superior anti-knock performance than split injection in SACI mode. In addition, the 
452 strategies and achieves the best performance with respect to knocking suppression.

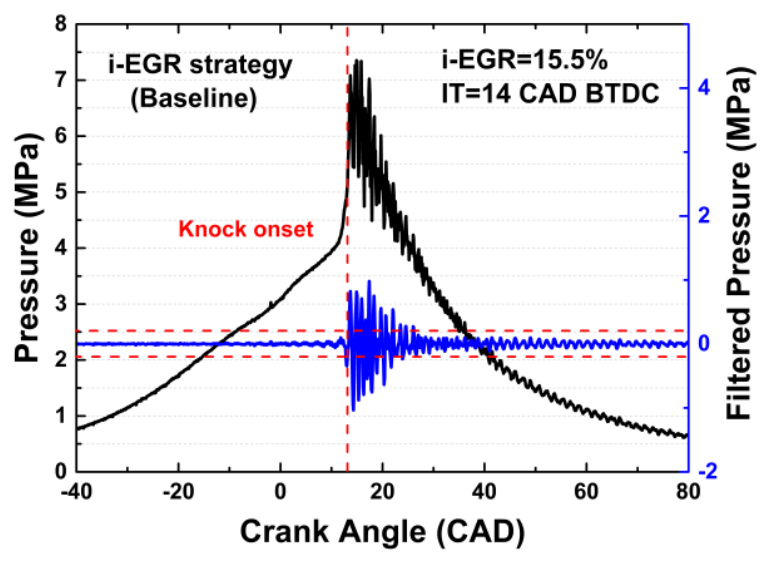

(a) i-EGR strategy (baseline)

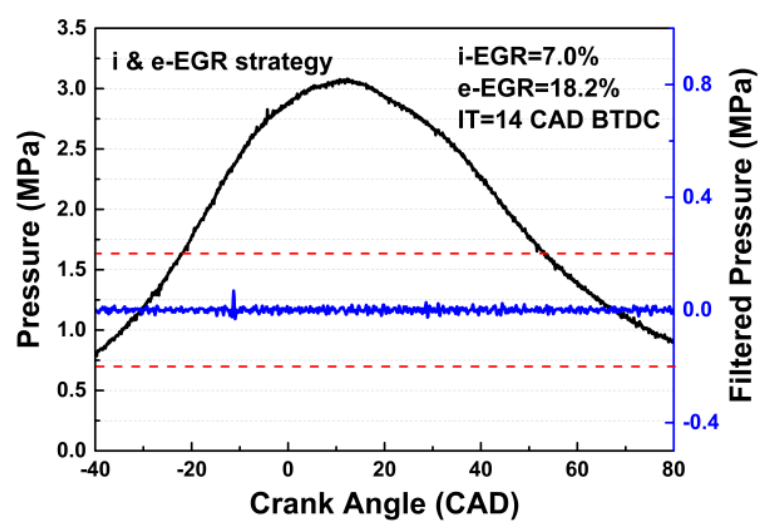

(c) i \& e-EGR strategy

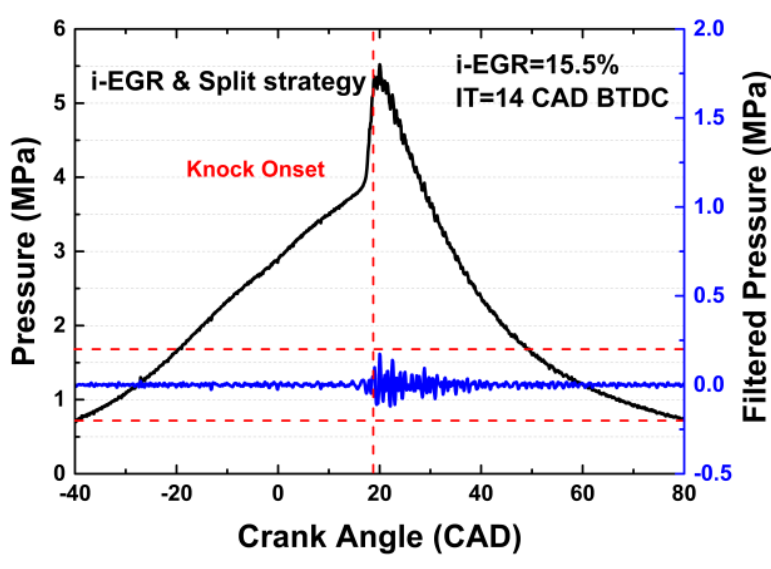

(b) i-EGR \& Split strategy

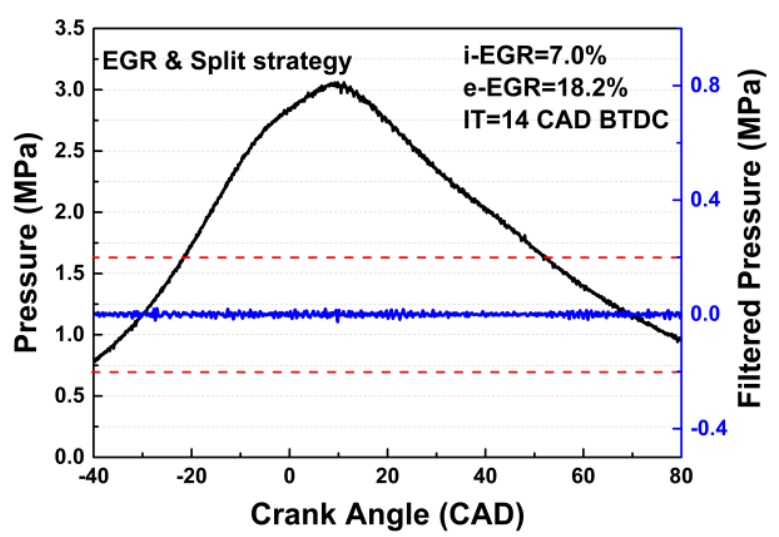

(d) EGR \& Split strategy

Fig. 15. Pressure and filtered pressure in SACI mode with different strategies

(EGR \& Split strategy, which includes the i-EGR, e-EGR and split injection strategies). 


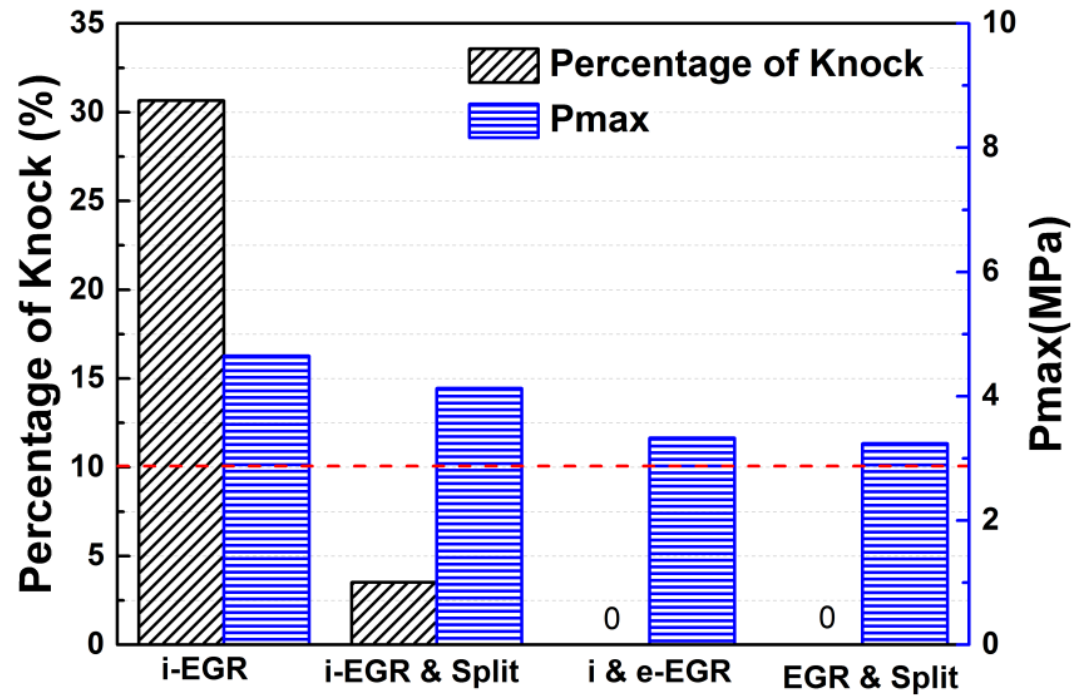

454 Fig. 16. Percentage of knock cycles and $P_{\max }$ in SACI mode with different strategies.

Figure 17 shows the BMEP and BSFC of the MBT points for different coupling strategies.

456 It can be seen from Fig. 17 that the BMEP and BSFC of the coupling strategies were optimised

457 relative to the baseline. This indicates that the coupling strategy considerably improves the

458 combustion characteristics of the SACI mode by suppressing knock. However, the power

459 output and fuel economy characteristics produced by the i \& e-EGR strategy are higher than

460 those produced by the i-EGR \& Split strategy. This is mainly because, when the i \& e-EGR

461 strategy is used, the combustion phase can be optimised by applying a more advanced IT

462 method on account of its better knock resistance. Based on this, the proposed EGR \& Split

463 strategy combines the advantages of i \& e-EGR and split injection, which provides it the best

464 combustion performance and an increase of approximately $0.1 \mathrm{MPa}$ in the BMEP and a

465 decrease of approximately $27 \mathrm{~g} / \mathrm{kW} \cdot \mathrm{h}$ in the BSFC, relative to the baseline. 


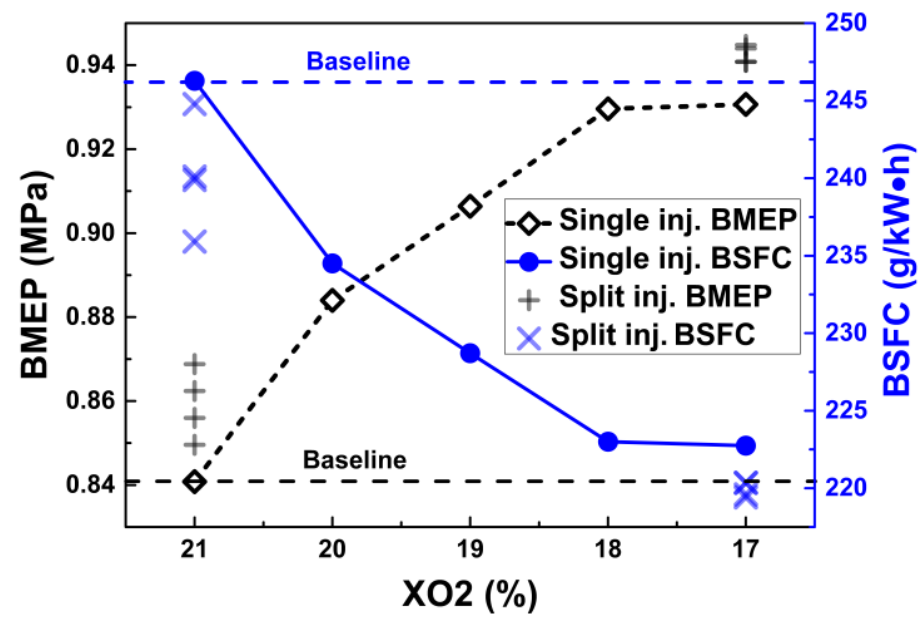

466

\section{Fig. 17. BMEPs and BSFCs results for the different coupling strategies}

\section{(where the $x$-coordinate represents the oxygen concentration, corresponding to different}

\section{EGR strategies at different oxygen concentrations, and inj. denotes injection).}

\section{Conclusions}

An experimental investigation was performed on the effects of coupling internal/external EGR and split injection on knock suppression and combustion characteristics in a natural aspirated single-cylinder GDI engine. The results can be summarised as follows:

(1) Experimental results of SACI combustion with i-EGR strategy indicate that the IT and i-EGR ratio are important parameters for controlling SACI combustion process. The i-EGR controls the combustion phase in SACI mode mainly by changing the initial in-cylinder temperature and intake mass flow rate. The $\mathrm{R}_{\mathrm{si}}$ drops as the i-EGR ratio increases. Similar to the traditional SI mode, the combustion phase is controlled by adjusting the IT in SACI mode. When the IT is excessively advanced, the excessive $R_{\mathrm{ci}}$ leads to knocking combustion. When the IT is excessively delayed, the basic heat release process is similar to that of the SI combustion and misfire cycles occasionally appear. 

increase in e-EGR ratio, MAPO decreases significantly and its probability distribution becomes more concentrated. The effects of e-EGR on knocking suppression are generally achieved by decreasing the in-cylinder temperature, diluting the fuel/air mixture and increasing the heat capacity, which result in longer ignition delay time, lower $\mathrm{R}_{\mathrm{ci}}$ value and lower knock intensity. In addition, the engine performance with i \& e-EGR strategy can be improved by more advancing IT and less negative work during NVO period compared to the only i-EGR strategy.

490

(3) The i-EGR \& Split strategy has a significant impact on knock suppression. The effect of split injection on knock suppression demonstrates the non-monotonic relationship at different levels of fuel stratification. The effect of the split injection strategy on knock suppression is also influenced by the initial in-cylinder temperature. When initial in-cylinder

494 temperature is high with large i-EGR ratio, the knock propensity first decreases and then 495 increases as the $\mathrm{SOI}_{2}$ is gradually retarded. However, when the i-EGR ratio is as low as $6.9 \%$, 496 which obtains a low initial in-cylinder temperature, the knock suppression effect of split 497 injection increases monotonically with the delay of $\mathrm{SOI}_{2}$.

(4) The EGR \& Split strategy combines the advantages of both split injection and e-EGR,

499 allowing the best knock resistance to be obtained. In addition, the coupling strategy that 500 combines internal/external EGR and split injection demonstrates the best engine performance,

501 with BMEP increasing approximately $0.1 \mathrm{MPa}$ and BSFC decreasing by approximately 27 $502 \mathrm{~g} / \mathrm{kW} \bullet \mathrm{h}$ relative to the baseline case. 
This work is supported by National Natural Science Foundation of China (Grant

506 China.

507 Nomenclature

\begin{tabular}{|c|c|c|c|}
\hline SI & Spark Ignition & MBT & $\begin{array}{l}\text { Minimum spark advance for Best } \\
\text { Torque }\end{array}$ \\
\hline $\mathrm{CI}$ & Compression Ignition & MAPO & $\begin{array}{l}\text { Maximum Amplitude of filtered } \\
\text { Pressure Oscillation }\end{array}$ \\
\hline $\mathrm{HCCI}$ & $\begin{array}{l}\text { Homogeneous Charge } \\
\text { Compression Ignition }\end{array}$ & EGR & Exhaust Gas Recirculation \\
\hline SACI & $\begin{array}{l}\text { Spark Assisted Compression } \\
\text { Ignition }\end{array}$ & PLIF & $\begin{array}{l}\text { Planar Laser } \quad \text { Induced } \\
\text { Fluorescence }\end{array}$ \\
\hline PPC & $\begin{array}{l}\text { Partially } \\
\text { Compression }\end{array}$ & VVT & Variable Valve Timing \\
\hline GDI & Gasoline Direct Inject & $\eta$ & Brake thermal efficiency \\
\hline CAD & Crank Angle Degree & $\lambda$ & Equivalence ratio \\
\hline BTDC & Before Top Dead Center & $\gamma$ & Ratio of specific heats \\
\hline NVO & Negative Valve Overlap & IMEP & Indicate Mean Effective Pressure \\
\hline IT & Ignition Timing & BMEP & Brake Mean Effective Pressure \\
\hline $\mathbf{R}_{\mathrm{ci}}$ & Ratio of CI heat release & BSFC & Brake Specific Fuel Consumption \\
\hline $\mathrm{R}_{\mathrm{si}}$ & Ratio of SI heat release & CR & Compression Ratio \\
\hline ROI & Ratio of Inject & WOT & Widely Open Throttle \\
\hline SOI & Start of Inject & EVC & Exhaust Valve Closing \\
\hline $\mathrm{P}_{\max }$ & Maximum Pressure & EVO & Exhaust Valve Opening \\
\hline HRR & Heat Release Rate & IVC & Intake Valve closing \\
\hline MFB & Mass Fraction Burned & IVO & Intake Valve closing \\
\hline
\end{tabular}

\section{References}

[1] H. Bendu, S. Murugan, Homogeneous charge compression ignition (HCCI) combustion:

512 [2] X.-C. Lü, W. Chen, Z. Huang, A fundamental study on the control of the HCCI combustion

513 and emissions by fuel design concept combined with controllable EGR. Part 2. Effect of operating conditions and EGR on HCCI combustion, Fuel 84 (2005) 1084-1092. 
515 [3] A.P. Singh, A.K. Agarwal, Combustion characteristics of diesel HCCI engine: An

516 experimental investigation using external mixture formation technique, Appl. Energy 99 (2012)

$517 \quad 116-125$.

518 [4] M. Sjöberg, J.E. Dec, Comparing late-cycle autoignition stability for single- and two-stage

519 ignition fuels in HCCI engines, Proc. Combust. Inst. 31 (2007) 2895-2902.

520 [5] Y. Yang, J.E. Dec, N. Dronniou, M. Sjöberg, Tailoring HCCI heat-release rates with partial

521 fuel stratification: Comparison of two-stage and single-stage-ignition fuels, Proc. Combust.

522 Inst. 33 (2011) 3047-3055.

523 [6] M. Canakci, An experimental study for the effects of boost pressure on the performance and

524 exhaust emissions of a DI-HCCI gasoline engine, Fuel 87 (2008) 1503-1514.

525 [7] J. Hunicz, A. Tmar, P. Krzaczek, Effects of Mixture Stratification on Combustion and

526 Emissions of Boosted Controlled Auto-Ignition Engines, Energies 10 (2017) 2172.

527 [8] Z. Wang, X. He, J.-X. Wang, S. Shuai, F. Xu, D. Yang, Combustion visualization and

528 experimental study on spark induced compression ignition (SICI) in gasoline HCCI engines,

529 Energy Convers. Manage. 51 (2010) 908-917.

530 [9] R.J. Middleton, L.K.M. Olesky, G.A. Lavoie, M.S. Wooldridge, D.N. Assanis, J.B. Martz,

531 The effect of spark timing and negative valve overlap on Spark Assisted Compression Ignition

532 combustion heat release rate, Proc. Combust. Inst. 35 (2015) 3117-3124.

533 [10] L.M. Olesky, J.B. Martz, G.A. Lavoie, J. Vavra, D.N. Assanis, A. Babajimopoulos, The

534 effects of spark timing, unburned gas temperature, and negative valve overlap on the rates of

535 stoichiometric spark assisted compression ignition combustion, Appl. Energy 105 (2013) 

hybrid combustion progress in a gasoline engine, SAE Pap. (2013), 2013-01-1662.

540 Charge Compression Ignition mode with commercial gasoline, SAE Pap. (2001), $541 \quad 2001-01-3610$.

[13] S.M. Begg, D.J. Mason, M.R. Heikal, Spark ignition and spark-assisted controlled auto-ignition in an optical gasoline engine, SAE Pap. (2009), 2009-32-0072.

[14] C.S. Yoo, Z. Luo, T. Lu, H. Kim, J.H. Chen, A DNS study of ignition characteristics of a 2985-2993.

547 [15] W.J. Glewen, R.M. Wagner, K.D. Edwards, C.S. Daw, Analysis of cyclic variability in 548 spark-assisted HCCI combustion using a double Wiebe function, Proc. Combust. Inst. 32 (2009) $549 \quad 2885-2892$.

550 [16] J. Benajes, A. García, V. Domenech, R. Durrett, An investigation of partially premixed 551 compression ignition combustion using gasoline and spark assistance, Appl. Therm. Eng. 52 552 (2013) 468-477.

553 [17] Z. Wang, J. Wang, S. Shuai, X. He, F. Xu, D. Yang, X. Ma, Research on spark induced 554 compression ignition (SICI), SAE Pap. (2009), 2009-01-0132. gasoline partially premixed compression ignition spark assisted combustion, Appl. Energy 104 
[19] J. Benajes, B. Tormos, A. Garcia, J. Monsalve-Serrano, Impact of spark assistance and multiple injections on gasoline PPC light load, SAE Pap. 7 (2014) 1875-1887. spark assisted compression ignition, Combust. Flame 157 (2010) 1106-1110. $101(2013)$ 622-633.

[22] L.M. Olesky, G.A. Lavoie, D.N. Assanis, M.S. Wooldridge, J.B. Martz, The effects of diluent composition on the rates of HCCI and spark assisted compression ignition combustion, Appl. Energy 124 (2014) 186-198.

[23] L. Manofsky, J. Vavra, D.N. Assanis, A. Babajimopoulos, Bridging the gap between HCCI and SI: Spark-Assisted Compression Ignition, SAE Pap. (2011), 2011-01-1179.

570 [24] X. Wang, H. Xie, L. Li, L. Xie, T. Chen, H. Zhao, Effect of the thermal stratification on 571 SI-CAI hybrid combustion in a gasoline engine, Appl. Therm. Eng. 61 (2013) 451-460.

572 [25] D. Li, Z. Wang, H. Liu, J.X. Wang, Combustion Mode Switch by Integrating 573 Stoichiometric ASSCI Mode in a Four-cylinder Gasoline SI/HCCI Engine, SAE Pap. (2014), $574 \quad 2014-01-1288$.

575 [26] H. Persson, J. Sjöholm, E. Kristensson, B. Johansson, M. Richter, M. Aldén, Study of fuel 576 stratification on Spark Assisted Compression Ignition (SACI) combustion with ethanol using 577 high speed fuel PLIF, SAE Pap. (2008), 2008-01-2401. 
578

579

580

581

582

583

584

585

586

587

588

589

590

591

592

593

594

595

596

597

598

[27] J. Benajes, S. Molina, A. García, J. Monsalve-Serrano, R. Durrett, Performance and engine-out emissions evaluation of the double injection strategy applied to the gasoline partially premixed compression ignition spark assisted combustion concept, Appl. Energy 134 (2014) 90-101.

[28] G. Marseglia, M. Costa, F. Catapano, P. Sementa, B.M. Vaglieco, Study about the link between injection strategy and knock onset in an optically accessible multi-cylinder GDI engine, Energy Convers. Manage. 134 (2017) 1-19.

[29] M. Pan, G. Shu, H. Wei, T. Zhu, Y. Liang, C. Liu, Effects of EGR, compression ratio and boost pressure on cyclic variation of PFI gasoline engine at WOT operation, Appl. Therm. Eng. 64 (2014) 491-498.

[30] D. Feng, H. Wei, M. Pan, Comparative study on combined effects of cooled EGR with intake boosting and variable compression ratios on combustion and emissions improvement in a SI engine, Appl. Therm. Eng. 131 (2018) 192-200.

[31] E.A. Ortiz-Soto, J. Vavra, A. Babajimopoulos, Assessment of residual mass estimation methods for cylinder pressure heat release analysis of HCCI Engines with negative valve overlap, J. Eng. Gas Turbines Power 134 (2012) 082802.

[32] R.G. Prucka, Z. Filipi, D.N. Assanis, D.M. Kramer, G.L. Ohl, An evaluation of residual gas fraction measurement techniques in a high degree of freedom spark ignition engine, SAE Pap. 1 (2008) 71-84.

[33] E. Galloni, Dynamic knock detection and quantification in a spark ignition engine by means of a pressure based method, Energy Convers. Manage. 64 (2012) 256-262. 
[34] G. Brecq, J. Bellettre, M. Tazerout, A new indicator for knock detection in gas SI engines,

600 International Journal of Thermal Sciences 42 (2003) 523-532.

601 [35] G. Shu, J. Pan, H. Wei, Analysis of onset and severity of knock in SI engine based on

602 in-cylinder pressure oscillations, Appl. Therm. Eng. 51 (2013) 1297-1306.

603 [36] Y. Liu, X. Shi, J. Deng, Y. Chen, M. Hu, L. Li, Experimental study on the characteristics of 604 knock under DI-HCCI combustion mode with ethanol/gasoline mixed fuel, SAE Pap. (2013), 605 2013-01-0544.

606 [37] U. Azimov, N. Kawahara, E. Tomita, UV-visible light absorption by hydroxyl and 607 formaldehyde and knocking combustion in a DME-HCCI engine, Fuel 98 (2012) 164-175.

608 [38] L. Zhou, J. Hua, H. Wei, K. Dong, D. Feng, G. Shu, Knock characteristics and combustion 609 regime diagrams of multiple combustion modes based on experimental investigations, Appl. 610 Energy 229 (2018) 31-41.

611 [39] Heywood, JohnB, Internal combustion engine fundamentals, McGraw-Hill, 1988.

612 [40] C.D. Rakopoulos, C.N. Michos, E.G. Giakoumis, Availability analysis of a syngas fueled 613 spark ignition engine using a multi-zone combustion model, Energy 33 (2008) 1378-1398.

614 [41] Z. Wang, J.X. Wang, S.J. Shuai, Q.J. Ma, New gasoline homogeneous charge compression 615 ignition combustion system using two-state direct injection and assisted spark ignition, Proc. 616 Inst. Mech. Eng. 220 (2006) 367-378.

617 [42] L. Cao, H. Zhao*, X. Jiang, Analysis of Controlled Auto-Ignition/HCCI Combustion in a 618 Direct Injection Gasoline Engine with Single and Split Fuel Injections, Combust. Sci. Technol $619180(2007)$ 176-205. 